\title{
APLIKASI PENILAIAN KINERJA KARYAWAN DI PT AERO GLOBE INDONESIA MENGGUNAKAN JAVA
}

\author{
Annisa Rahmah \\ Program Studi Teknik Informatika, Fakultas Teknik dan Ilmu Komputer, \\ Universitas Indraprasta PGRI \\ Jl. Raya Tengah No. 80, Kel. Gedong Kec. Pasar Rebo, Jakarta Timur \\ anniisaa25@gmail.com
}

\begin{abstract}
Abstrak
Permasalahan yang dialami oleh PT Aero Globe Indonesia dalam hal penilaian kinerja karyawan, yaitu proses pendataan dan penilaian serta pelaporannya masih bersifat manual. Hal tersebut membuat pembukuan mengalami keterlambatan dari pihak HRD perusahaan karena belum ada nya suatu sistem informasi dalam menangani permasalahan yanga ada saat ini. Dalam hal ini peneliti menggunakan metode waterfall dalam penyelesaian permasalahan tersebut, dengan harapan metode ini menjadi suatu solusi langkah-langkah dalam penyelesaiain suatu sistem informasi yang akan dirancang. Metode waterfall dalam penelitian ini adalah dengan tahapantahapan seperti rekayasa sistem, analisis, desain, coding, testing, dan maintenance. Tujuan dari sistem penilaian kinerja karyawan ini dibuat untuk mengetahui bagaimana produktivitas kerja semua karyawan yang berada di lingkungan PT Aero Globe Indonesia dan dapat membantu HRD dalam memberikan keputusan SDM dengan memberikan data setiap karyawan secara berkala kepada pimpinan. Hasil dari penelitian ini dengan adanya aplikasi sistem penilaian kinerja karyawan yang terkomputerisasi dan tersimpannya suatu data dengan baik didalam database dapat menciptakan aplikasi untuk pendataan data karyawan, data penilaian kinerja karyawan serta pelaporan lebih akurat yang sesuai dengan kebutuhan perusahaan. Dengan aplikasi yang diciptakan membuat seluruh elemen divisi khususnya admin dan HRD dapat meningkatkan performa kinerja nya dengan baik dan meminimalisir terjadi nya suatu kesalahan dalam proses pendataan serta penilaian kinerja karyawan didalam sistem.
\end{abstract}

Kata Kunci: Aplikasi, Kinerja Karyawan, Java, MySQL

\begin{abstract}
The problems experienced by PT Aero Globe Indonesia in terms of employee performance assessment, namely the data collection and assessment process and reporting are still manual. This makes bookkeeping experience delays from the company's HRD because there is no information system in dealing with the current problems. In this case, researchers use the waterfall method in solving the problem, in the hope that this method becomes a solution steps in completing an information system to be designed. Waterfall methods in this research are with stages such as system engineering, analysis, design, coding, testing, and maintenance. The purpose of this employee performance assessment system is made to find out how the work productivity of all employees who are in the environment of PT Aero Globe Indonesia and can assist HRD in providing HR decisions by providing data on each employee periodically to the leadership. The results of this study with the application of a computerized employee performance assessment system and the store of a good data in the database can create applications for the collection of employee data, employee performance assessment data and more accurate reporting that suits the needs of the company. With the application created, all division elements, especially admin and HRD, can improve their performance well and minimize an error in the data collection process and assessment of employee performance in the system.
\end{abstract}

Keywords: Application, Employee Performance, Java, MySQL

\section{PENDAHULUAN}

Teknologi saat ini melakukan perkembangan sangat cepat dari aspek ekonomi, barang hingga jasa asuransi yang semakin berkembang diberbagai sektor. Dengan hal tersebut membuat suatu aktivitas perekonomian dilakukan dengan antara kedua belah pihak yang telah melalui suatu kesepakatan 
bersama. Permasalahan yang terdapat di PT Aero Globe Indonesia terkait pendataan data karyawan dan penilaian kinerja karyawan. Kinerja karyawan pada bagian ticketing yang menjadi kriteria pengukuran atau penilaian yang diberikan oleh Supervisor adalah disiplin dalam hal waktu bekerja, informasi tentang ticket apa saja yang dijual ke customer, loyalitas karyawan terhadap perusahaan, kerjasama dalam tim yang di bentuk oleh perusahaan serta penjualan yang selalu ada peningkatan di setiap bulannya.Selain itu kinerja karyawan bagian ticketing ini di nilai oleh beberapa customer yang bertujuan untuk mengetahui bagaimana perkembangan kinerja karyawan yang ada saat ini salah satu kriteria yang menjadi pertimbangannya antara lain sikap karyawan dalam melayani customer, pengetahuan tentang tiket yang akan di jual, pelayanan yang di berikan oleh karyawan apakah dapat memuaskan customer itu sendiri atau tidak, respon karyawan jika ada keluhan atau ada hal yang tidak dapat customer pahami.

Penilaian kinerja karyawan PT. Aero Globe Indonesia bertujuan untuk memotivasi individu karyawan dan sebagai penentu dalam pemberian reward karyawan namun selama ini belum optimal dikarenakan adanya kecendrungan terpusat pada penilaian kinerja yang menyebabkan penilaian menjadi tidak objektif serta belum ada pembobotan pada kriteria penilaian sehingga belum diketahui kriteria mana yang paling mempengaruhi kinerja karyawan (Amalia \& Utami, 2018). Proses penginputan data dan laporan ini masih dilakukan secara manual, sehingga data yang didapat seringkali tidak valid (Setiobudi, 2017), misalnya ketika bagian administrasi membutuhkan informasi mengenai data karyawan yang akan digunakan dalam proses penilaian kinerja karyawan oleh HRD. Pengelolaan data penilaian kinerja karyawan yang dilakukan secara terkomputerisasi ini mengandalkan kemajuan teknologi informasi yang dapat meminimalisir kendala yang ada dan dapat memberikan hasil yang baik (Saefudin \& Wahyuningsih, 2014).

Dengan permasalahan tersebut, perlu ada nya suatu sistem yang terkomputerisasi dalam penyelesaiannya. Sistem adalah sekelompok unsur yang erat hubungannya satu dengan yang lain, yang berfungsi bersama-sama untuk mencapai tujuan (Sutabri, 2012). Suatu sistem yang dikembangkan merupakan sebagai instruksi yang dapat dikelola oleh programmer dalam menjalani perintah script tersebut (Tyoso, 2016). Pembangunan sistem yang harus diketahui ini sekumpulan aktivitas yang biasa digambarkan bagaimana sistem ini dapat berjalan dengan semestinya sesuai dengan instruksi. Dengan ini tujuannya untuk menghasilkan suatu software yang dibutuhkan oleh calon user kita dalam penyelesaian masalahnya (Satzinger, J. W., Jackson, R. B., Burd, n.d.).

Aplikasi ini dapat memudahkan pekerjaan kita dalam melaksanakan pembuatan laporan dan dapat memudahkan perusahaan dalam pendataan data karyawan, data penilaian kinerja karyawan dan pelaporan yang diproses secara terkomputerisasi. Pada aplikasi tersebut, kita dapat melihat seluruh data kar, dan penjualan yang didapat dari CV Rochman Rejeki dan laporan yang lebih baik dan akurat (Ali, 2019).

\section{PENELITIAN RELEVAN}

Penelitian oleh (Mahmudi, 2015) yang berjudul Sistem Informasi Penilaian Kinerja Dosen dan Karyawan Berbasis Web memiliki hasil penelitian proses penilaian kinerja yang saat ini dilakukan dengan bersifat manual dengan cara mengisi form kuesioner, melalui mahasiswa, teman-teman sejawat dan pimpinan. Hasil penelitian yang sudah dilakukan untuk proses pengembangan sistem informasi penilaian berbasis web. Hasil penelitian berupa aplikasi dengan informasi hasil evaluasi kinerja dosen dan karyawan yang digunakan sebagai dasar untuk melakukan perbaikan kinerja maupun sebagai dasar dalam pemberian reward untuk dosen dan karyawan.

Lalu ada penelitian yang dilakukan oleh (Natanael \& Mulyono, 2017) yang berjudul Analisis dan Perancangan Sistem Informasi Penilaian Kinerja Karyawan pada PT. BPR Universal Sentosa memiliki hasil penelitian untuk menganalisa dan merancang sistem informasi penilaian kinerja karyawan dengan menerapkan sistem informasi penilaian kinerja berbasis web. Kerangka kerja penelitian ini terdiri dari studi literatur, pengumpulan data, analisis data, pengembangan sistem, dan pembuatan laporan. Metode pengembangan sistem peneliti melakukan rancangan use case, activity diagram, class diagram serta model waterfall dan prototype. Sistem informasi penilaian kinerja karyawan ini dapat melakukan 
proses penilaian kinerja dan mengelola data karyawan dengan baik agar mengefektifkan dan mengefisiensikan proses penilaian kinerja dan mempercepat waktu serta meminimalisasi tingkat kesalahan saat memasukkan data.

\section{METODE PENELITIAN}

Peneliti menggunakan metode Grounded Research dalam penyelesaian penelitian ini. (Sugiyono, 2016) Grounded Research adalah suatu metode yang berfokus kepada fakta serta menggunakan cara analisis yang menerapkan suatu konsep-konsep untuk membuktikan suatu teori dan dapat dikembangkan dalam proses pengolahan data analisis dalam waktu yang bersamaan. Tujuan dari metode grounded research ini mengadakan generalisasi empiris serta ditetapkannya suatu konsep dalam mencapai suatu teori sehingga dikembangkan. Penelitian juga bertujuan untuk menjabarkan suatu konsep, yang bisa diartikan mencerna beberapa contoh kasus sehingga dapat dibandingkan untuk beberapa kasus sebagai referensi. Perbandingan ini akan memaparkan suatu unsur-unsur baru yang dapat dipelajari.

Studi lapangan ini peneliti lakukan untuk melihat langsung terhadap penerapan sistem penilaian kinerja karyawan di PT Aero Globe Indonesia. Dalam studi lapangan ini dipergunakan teknik pengumpulan data antara lain dengan cara observasi yang dimana peneliti mengamati proses-proses yang terdapat pada PT Aero Globe Indonesia dari proses pendataan data karyawan, data penilaian karyawan, data hasil penilaian karyawan.

\section{HASIL DAN PEMBAHASAN}

\section{Analisa Permasalahan}

Dari hasil penelitian yang dilakukan, ditemukan permasalahan yang ada pada PT Aero Globe Indonesia, yaitu:

1. Form penilaian yang masih digunakan dalam bentuk fisik (kertas), sehingga apabila terjadi kerusakan atau hilangnya data, Admin harus memproses mengisi form ulang.

2. Penginputan data nilai ke dalam komputer masih harus melalui beberapa kali proses pemeriksaan untuk mengurangi terjadinya kesalahan, sehingga dirasa kurang efisien.

3. Penginputan data nilai masih harus menunggu Supervisor dan Customer menyelesaikan proses penilaian, sehingga memungkinkan terjadinya keterlambatan terjadinya pembuatan laporan

4. Penyimpanan data nilai belum terstruktur dengan baik.

\section{Alternatif Penyelesaian Masalah}

Dari hasil analisa yang dilakukan, maka dapat disimpulkan bahwa PT. Aero Globe Indonesia memerlukan sebuah sistem yang dapat mengelola perhitungan data-data nilai karyawan. Sebuah sistem yang juga dapat menangani permasalahan beban pekerjaan Adminyang terlalu banyak memproses pemeriksaan dan nilai. Sistem yang dibutuhkan juga merupakan sebuah sistem yang dapat mengelola laporan-laporan data nilai karyawan agar lebih mudah ditemukan dan mengurangi kemungkinan kesalahan dalam pengisian dat nilai.

Untuk mengatasi masalah-masalah tersebut maka akan diberikan sistem yang dapat mengelola data nilai karyawan, memproses perhitungan nilai akhir dan mengelola seluruh laporan data nilai sehingga memudahkan Admin dalam pembuatan laporan kepada HRD. 


\section{Diagram Konteks}

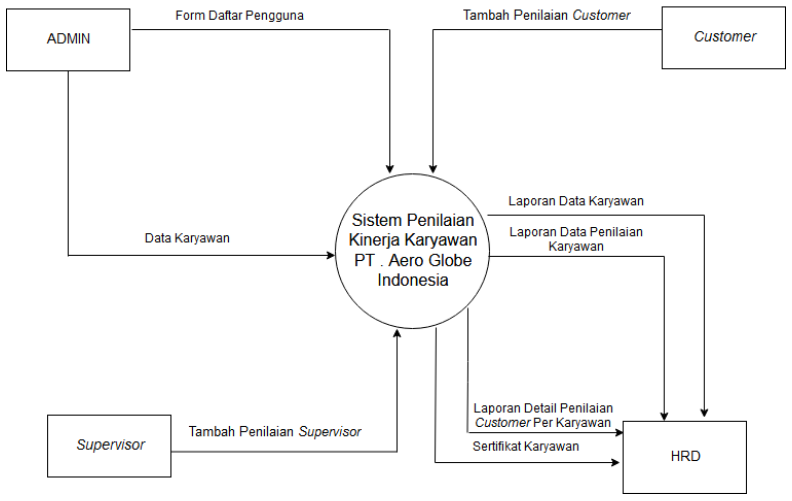

Gambar 1. Diagram Konteks

\section{Normalisasi}

Teknik untuk merancang tabel basis data relasional guna meminimalisir duplikasi data sehingga dapat menjaga basis data dari permasalahan unomaly update dan proses pengelompokan atribut data yang membentuk entitas sederhana, nonredundan, fleksibel, dan mudah beradaptasi, Sehingga dapat dipastikan bahwa database yang dibuat berkualitas baik (Pahlevi, 2013)

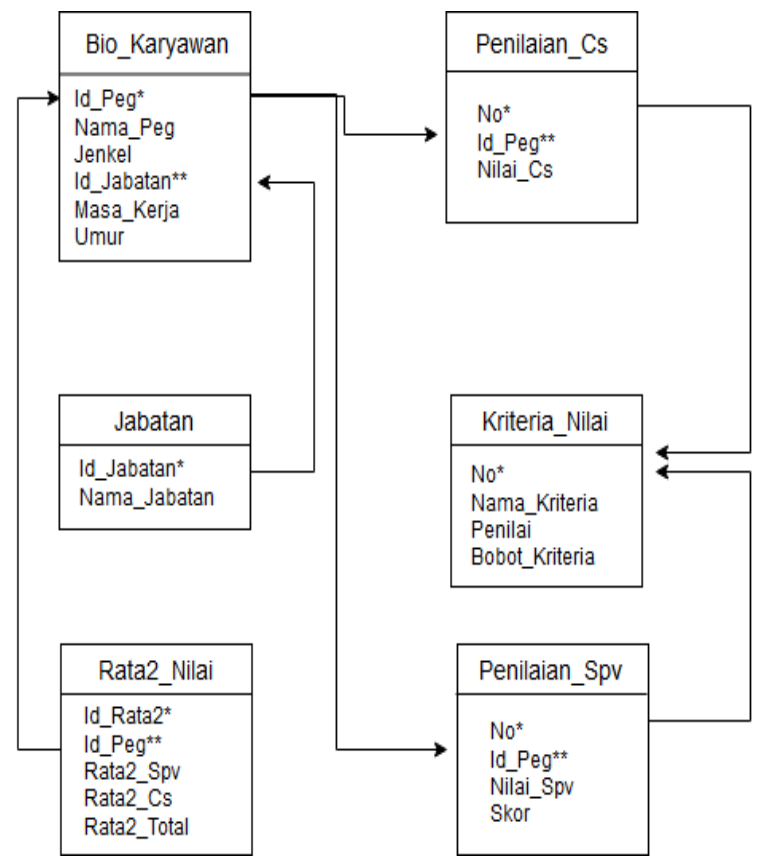

Gambar 2. Normalisasi

\section{Entity Relationship Diagram}

Entity Relationship Diagram merupakan bentuk paling awal dalam melakukan perancangan basis data relasional. Dari banyaknya entitas yang terdapat didalam suatu diagram saling berhubungan dan di setiap-setiap entitas harus memiliki atribut yang dimana setiap atribut tersebut memiliki primary key. (Shalahudin, 2015) 


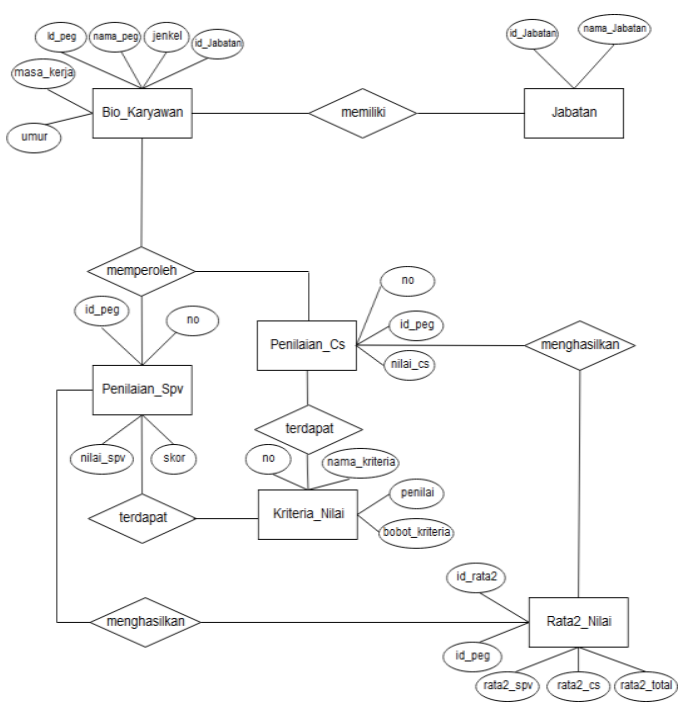

Gambar 3. Entity Relationship Diagram

\section{Tampilan Layar Sistem}

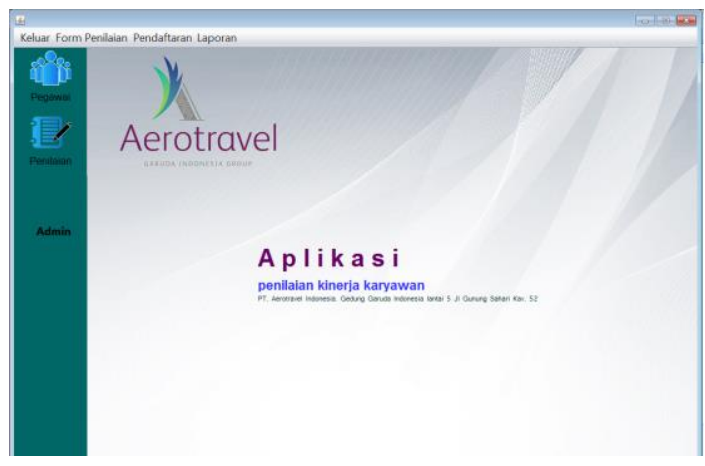

Gambar 4. Tampilan Layar Menu Utama

Layar di atas menampilkan tampilan Menu Utama pada Sistem Penilaian Kinerja Karyawan pada PT Aero Globe Indonesia Pada layar utama tersedia menu bar yang terdiri dari master data yang digunakan untuk memasukkan data yang berkaitan dengan data karyawan, data penilaian karyawan, data penilaian SPV, data penilaian customer, dan laporan-laporan.

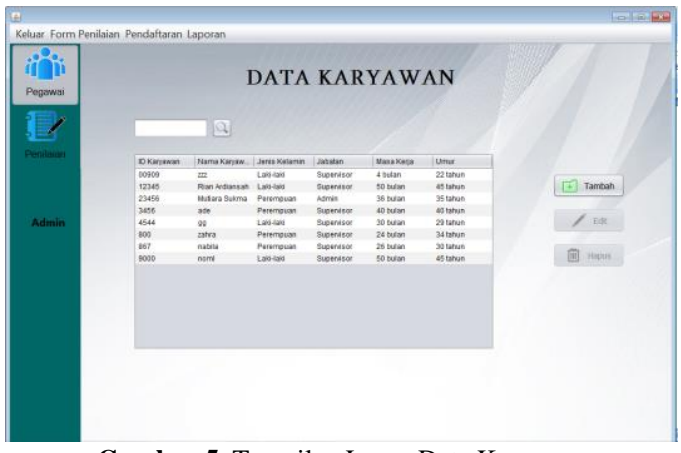

Gambar 5. Tampilan Layar Data Karyawan 
Layar di atas menampilkan tampilan form data karyawan. Pada layar form data karyawan untuk meng-input data karyawan yang terdiri dari ID Karyawan, Nama Karyawan, Jenis Kelamin, Jabatan, Masa Kerja dan Umur.

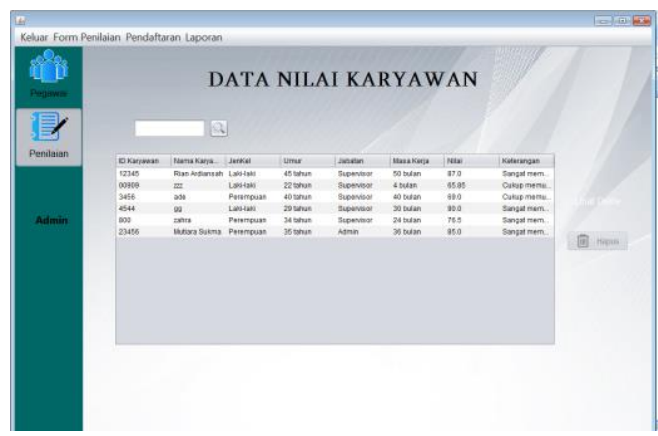

Gambar 6. Tampilan Layar Data Nilai Karyawan

Layar di atas menampilkan tampilan form data nilai karyawan. Pada layar form data nilai karyawan untuk meng-input data nilai karyawan yang terdiri dari ID Karyawan, Nama Karyawan, Jenis Kelamin, Jabatan, Masa Kerja, Nilai dan Keterangan

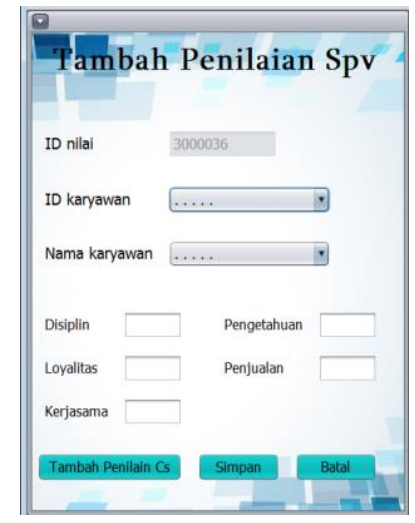

Gambar 7. Tampilan Layar Penilaian SPV

Layar di atas menampilkan tampilan form penilaian SPV. Pada layar form penilaian SPV untuk meng-input penilaian SPV yang terdiri dari ID Nilai, ID Karyawan, Nama Karyawan, dan Penilaian.

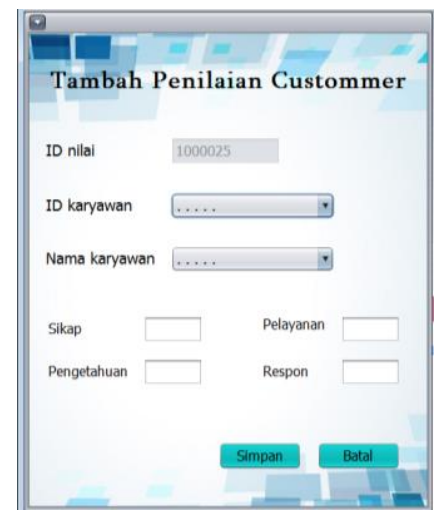

Gambar 8. Tampilan Layar Laporan Data Customer 
Layar di atas menampilkan tampilan form penilaian customer. Pada layar form penilaian customer digunakan untuk input penilaian customer terdiri ID Nilai, ID Karyawan, Nama Karyawan, dan Penilaian.

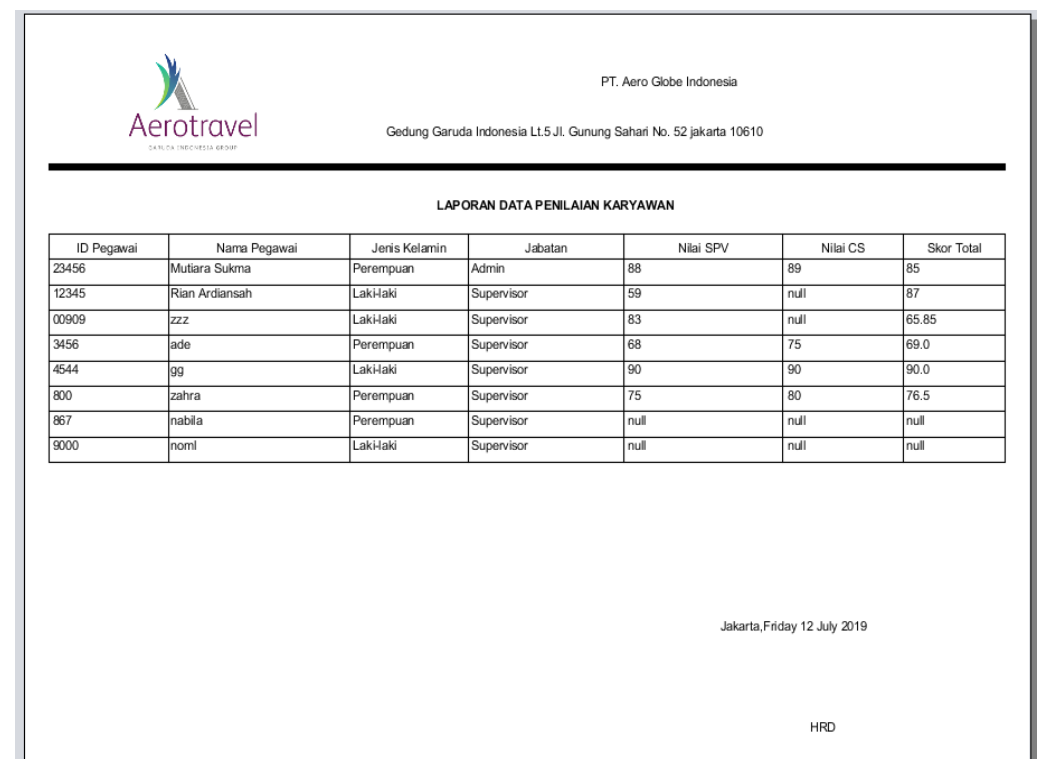

Gambar 9. Tampilan Layar Laporan Data Penilaian Karyawan

Layar di atas menampilkan tampilan form laporan penilaian karyawan. Pada layar form penilaian karyawan digunakan untuk mengecek laporan penilaian karyawan terdiri ID Karyawan, Nama Karyawan, Jenis Kategori, Jabatan, Nilai SPV, Nilai CS, Skor Total.

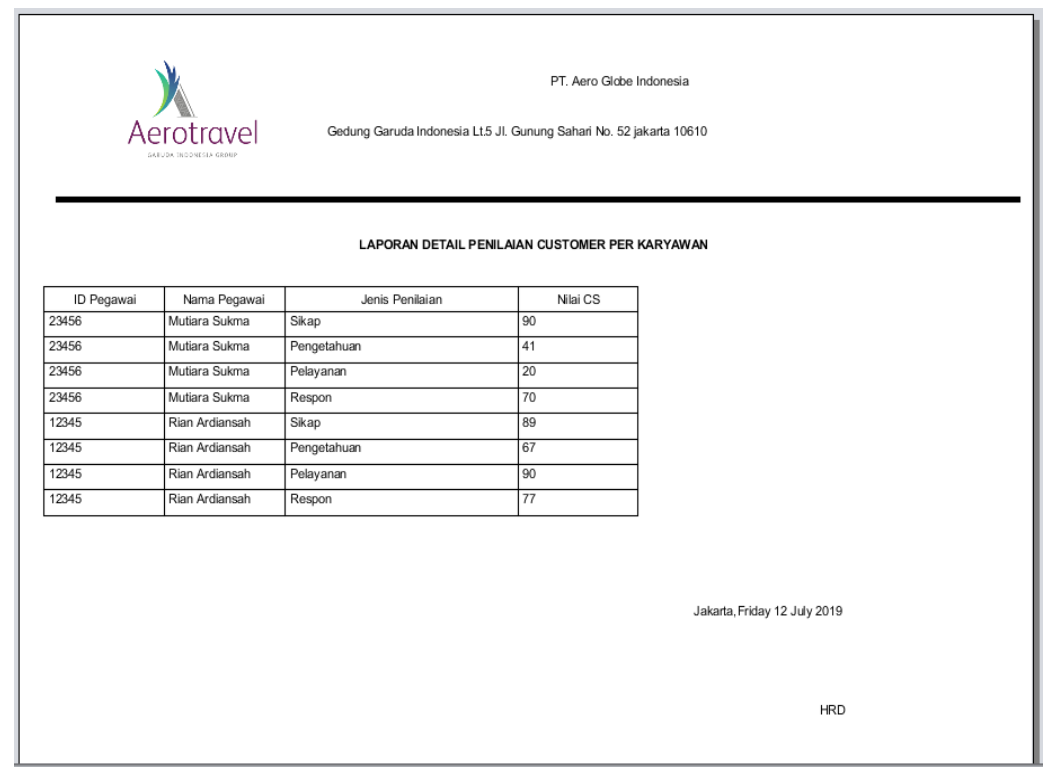

Gambar 10. Tampilan Layar Data Penilaian Customer 
Layar di atas menampilkan tampilan form laporan penilaian customer pada layar form penilaian customer digunakan untuk mengecek laporan penilaian customer terdiri ID Karyawan, Nama Karyawan, Jenis Penilaian dan Nilai CS.

\section{SIMPULAN}

Aplikasi Penilaian Kinerja Karyawan ini dirancang sebagai solusi bagi pihak perusahaan PT. Aero Globe Indonesia untuk mengelola hasil nilai kinerja karyawan secara cepat dan tepat dibanding secara manual sehingga dalam mencapai pekerjaan dapat diwujudkan secara lebih maksimal. Aplikasi Penilaian Kinerja ini dibuat bersifat intern, artinya pengguna program ini hanya kalangan tertentu yang memiliki hak akses terhadap aplikasi ini yaitu Admin dan HRD.

\section{DAFTAR PUSTAKA}

Ali, A. F. (2019). Rancang Bangun Aplikasi Penjualan Barang Berbasis Java Programming. Simtika.

Amalia, R. M., \& Utami, D. Y. (2018). Pemberian Reward Berdasarkan Penilaian Kinerja Karyawan Dengan Metode Ahp Pada Pt. Anugerah Protecindo. JITK (Jurnal Ilmu Pengetahuan Dan Teknologi Komputer).

Mahmudi, A. A. (2015). Sistem Informasi Penilaian Kinerja Dosen Dan Karyawan Berbasis Web. Surya Informatika.

Natanael, B., \& Mulyono, H. (2017). Analisis Dan Perancangan Sistem Informasi Penilaian Kinerja Karyawan Pada PT . BPR Universal Sentosa. Jurnal Manajemen Sistem Informasi.

Pahlevi, D. S. M. (2013). Tujuh Langkah Praktis Pembangunan Basis Data. Jakarta: Elex Media Komputindo.

Saefudin, \& Wahyuningsih, S. (2014). Sistem Pendukung Keputusan Untuk Penilaian Kinerja Pegawai Menggunakan Metode Analytical Hierarchy Process (Ahp) Pada RSUD Serang. Jurnal Sistem Informasi.

Satzinger, J. W., Jackson, R. B., Burd, S. D. (n.d.). System Analysis and Design in A Changing World. USA: Cengage Learning.

Setiobudi, E. (2017). Analisis Sistem Penilaian Kinerja Karyawan Studi pada PT. Tridharma Kencana. JABE (Journal of Applied Business and Economic). https://doi.org/10.30998/jabe.v3i3.1768

Shalahudin, A. . R. dan. (2015). Rekayasa Perangkat Lunak Terstruktur dan Berorientasi Objek. Bandung: Informatika Bandung.

Sugiyono. (2016). Metode Penelitian Kuantitatif, Kualitatif dan R\&D. Bandung: PT Alfabet.

Sutabri, T. (2012). Analisis Sistem Informasi. Yogyakarta: Andi.

Tyoso, J. S. P. (2016). Sistem Informasi Manajemen. Yogyakarta: DeePublish. 